evidence of brain damage (deviation from normal brain structure) and is it reponsible for a deficit (impairment or loss or alteration of intelligence and emotion, and behavioral abnormality)?; 2) Is the deficit a contributing cause of the defendant's crime?; 3) Without the deficit and resulting behavior, would the crime not have happened? of 14 death row juveniles who had committed capital crimes, 11 had suffered head trauma, 9 had abnormal EEGs or neurologic examinations, and 12 gave a history of physical or sexual abuse (Lewis DO, Pincus JH et al. Am I Psychiatry 1988; 145;584). Brain damage may unleash violence, but it does not explain it, according to Hachinski V. (Arch Neurol Aug 1993; $\underline{50: 871) .}$

A study of frontal lobe-subcortical circuits in the mediation of a wide range of human behavioral disorders, reported from the Departments of Neurology, Psychiatry and Biobehavioral Sciences, UCLA School of Medicine, Los Angeles, CA (Cummings JL. Arch Neurol Aug 1993; $\underline{50}: 873-880$ ) demonstrates that we should not entirely dismiss a possible role of brain damage in crimes of violence.

\title{
ADHD AND DRIVING RISKS
}

A 3- to 5- year follow-up survey of driving-related risks and outcomes in 35 adolescents and young adults with attention deficit hyperactivity disorder (ADHD) and 36 control subjects is reported from the Departments of Psychiatry, Neurology, and Pediatrics, University of Massachusetts Medical Center, Worcester, MA. ADHD subjects had a significantly greater risk than controls for traffic citations, especially for speeding, motor vehicle crashes, automobile injuries, and unsound driving habits. A subgroup of teenagers with ADHD complicated by oppositional defiant and conduct disorders were at highest risk for deviant driving skills/habits and negative driving-related outcomes. Even before receiving a license, the ADHD group was three times more likely to have driven without a valid license than the control group. During their brief driving careers, the ADHD group was involved in a total of 54 crashes compared with 16 for controls, and they were four times as likely to have been at fault. (Barkley RA et al. Driving-related risks and outcomes of attention deficit hyperactivity disorder in adolescents and young adults: A 3- to 5-year follow-up survey. Pediatrics Aug 1993;92:212-218). (Reprints: RA Barkley PhD, Dept of Psychiatry, University of Massachusetts Medical Center, 55 Lake Avenue North, Worcester, MA 01655).

COMMINT. These results corroborate previous studies showing a correlation between ADHD in adolescents and young adults and an increased rate of motor vehicle crashes, especially in those not treated with stimulant medication. (Weiss G, Hechtman LT. Hyperactive Children Grown Un. New York, NY: Guilford Press; 1986). ADHD patients who 
continued to take stimulant medication as young adults had no more crashes than a control group. Counselling of ADHD patients and their parents regarding risks of driving and increased potential for crashes and injuries is important. The authors suggest that clinicians may wish to consider continued therapy with methylphenidate in adolescents with severe ADHD in the hope of reducing the risk of driving injuries.

\section{SEIZURE DISORDERS}

\section{PROGNOSIS OF 'LENGTHY' FEBRILE CONVULSIONS}

The outcome of children with status epilepticus (afebrile seizure $>30$ min) or lengthy febrile convulsions ( $>30 \mathrm{~min}$ ) is reported by a British population based cohort study group that followed 16004 neonatal survivors born in one week in 1970 and assessed them after 5 and 10 years. Febrile convulsions (FC) in 398 children were lengthy in 19 (4.8\%). Children with lengthy FC had a greater risk of afebrile seizures than those with FC $<30 \mathrm{~min}$ $(4 / 19[21 \%] \vee 13 / 379$ [3.4\%] ), but the rate was lower than in the status group $(14 / 17$ [82\%] ) and none died. Of 84 children with afebrile seizures, 18 (21\%) had status epilepticus, and 2 died: one of cerebellar tumor hemorrhage and the other as a result of encephalitis and pneumonia. Neither death was directly due to status epilepticus. In 10 of 33 survivors of lengthy FC or status, measures of IQ were abnormal but 8 had preceding developmental delay or neurologic abnormality. (Verity CM, Ross EM, Golding J. Outcome of childhood status epilepticus and lengthy febrile convulsions: findings of national cohort study. BMI 24 July 1993;307:225-228). (Respond: Dr CM Verity, Department of Paediatrics, Addenbrooke's Hospital, Cambridge CB2 $2 \mathrm{QQ}$ UK).

COMMENT. This population based study gives a more optimistic outcome of lengthy febrile convulsions and status epilepticus than hospital based studies. A poor outcome was determined more by the underlying cause than the seizure itself. In a prospective study of 110 patients with febrile seizures followed for up to 2 years, the incidence of afebrile seizures and of EEG seizure discharges was significantly greater in patients with 'prolonged' febrile seizures $>20$ min than in those with short seizures <20 min. (Millichap JG et al. Neurology 1960;10:643). Both duration of the seizure and the EEG were predictive of outcome.

Pavone L, Galli V et al, Universities of Catania and Modena, Italy, report a follow-up study of 204 children who suffered febrile (FS) and afebrile seizures (AFS) within a 12 month period. . EEG specific abnormalities found in $69(33 \%)$ were associated with AFS recurrences in $94 \%$. EEG seizure discharges were predictive of further AFS. (Child's Nerv Syst June 1993;9:154-156). 